\title{
Research on Classification of Multimedia Network Public Opinion
}

\author{
Zhen-Hao YE ${ }^{1, a}$, Jing-Nan $\mathrm{HU}^{2, b,{ }^{*}}$, Ge GAO ${ }^{3, c}$ \\ ${ }^{1}$ School of Management, Jilin University, Changchun, China \\ ${ }^{2}$ School of Management, Jilin University, Changchun, China \\ ${ }^{3}$ School of Management, Jilin University, Changchun, China \\ ayezh0913.jlu@gmail.com, bhujingnan1996@outlook.com, ’gaogew@126.com \\ * Jingnan $\mathrm{Hu}$
}

Keywords: network public opinion, taxonomy, classification system.

\begin{abstract}
The paper aims to explore an important prerequisite factor of research on network public opinion and provide a reference to deal with network public opinion emergency. First, the paper collects relevant literatures about multimedia network public opinion, and then summarizes them based on the existing taxonomies. At last, the paper summarizes the significance of the research on classification of multimedia network public opinion.
\end{abstract}

\section{Introduction}

Network public opinion, which refers to different public views about popular social issues on the Internet, is a form of public opinion and is a network-spreaded expression of public who hold strong and tendentious opinions when they consider some hot spots in real lives. "Sociological Interpretation of Net-Mediated Public Sentiment", [1] a book written by Zhang Chunhua, the member of Academy of social science in Shanxi Province, used "net-mediated" to describe "media of the network". The first explanation of sentiment in "Merriam-Website Dictionary" is an attitude, idea or judgment generated by emotion. [2] And what Zhang Chunhua emphasizes is the public attitude in media network.

In order to study network public opinion more targetedly, modern scientists classify the public opinion and raise their own viewpoints about the standards and principles of classification, many of which, however, do not have subject frames and strict and uniform categories at all. And because there are too many taxonomies of public opinion, which make researches chaotic, this paper will analyze existing studies and then conclude four types of representative classifications, hoping to help researchers studying public opinion form big picture of it and support government to deal with network public opinion emergency.

\section{Taxonomy of the Content of Public Opinion}

In various taxonomies, those based on the content of public opinion are the most confusing. According to Chinese Propaganda Department Public Opinion Information Bureau [3], based on the content, network public opinion is divided into five types, which are political network public opinion, economic network public opinion, cultural network public opinion, social network public opinion and complex network public opinion.

According to some websites, Xinhua net divides network public opinion into ministries' public opinion, local public opinion, and business public opinion; People net divides it into corporate public opinion, official public opinion, and political public opinion; Chinese public opinion net divides it into political public opinion, military public opinion, safety supervision public opinion, business public opinion, local public opinion, picture public opinion and celebrities' public opinion. Content taxonomy plays an important role in further study concerning network public opinion. Kui Zheng emphasizes this importance in his public-opinion analyzing method [4]. The method says that after gaining from reading files, results still need to be classified again based on the content 
taxonomy. Content taxonomy can be used as a premise to study network public opinion in depth and help researchers do the survey targetedly, preventing omissions.

But in summary, content classification is still difficult, and almost all those classifications lack the scientific basis. The Chinese public opinion net, for example, divides the public opinion into political public opinion, military public opinion, safety supervision public opinion and so on. For one thing, these columns are likely to have cross repetition since it is difficult to distinguish the differences among them. And the same difficulty occurs in categorizing ministries' public opinion and local public opinion, according to the classification of Xinhua net. For another, the contents of each column can not interpret the body section, while at the same time the reclassification of the columns' content is much more difficult, making the concept shallow and content confusing. For instance, picture public opinion, whose range is wide, has many components that other columns do have.

Thus, it is difficult to classify the public opinion without any directional premise, but setting classification angles or requirements can help category. For example, when considering the classification on the view of safety supervision of public opinion, people can focus on the public opinions that have high risk or bring serious consequences, center on the realistic need of supervision, and combine annual social hot spots. As a result, public opinion can be classified as government management, major accidents, natural disasters, education, health, agriculture, employment, transportation, public safety, property, military, and diplomatic. This classification not only has a strong target, but also avoids content missing.

\section{Taxonomy of the Body and Medium Elements}

When constructing the criteria system for the classification of network public opinion, Wang Guohua, Feng Wei, and Wang Yalei select two dimensions: the criteria system uses the behaviors of stimulus as horizontal dimension and the propagation process of the network public opinion as vertical dimension [5].

That criteria system uses the behaviors of stimulus can be subdivided into: (1) government or non-government behavior; (2) single group behavior or multiple group behavior. That criteria system uses the propagation process can be subdivided into: (1) the level of spread participation; (2) the strength of spread influence; (3) whether have offline action or not.

Based on the above dimensions, public opinion can be divided into weak network public opinion, strong network public opinion and fluctuating network public opinion. Weak network public opinion, from the point of view of stimulus' behaviors, is mainly caused by the behaviors of single non-governmental group, with the result that the participation of internet users and media is not high; strong network public opinion cause by government itself or by multiple groups, has a high participation of internet users and media, and should be paid close attention; fluctuating network public opinion, which is more complex, can be understood as different evolutionary phase of network public opinion showing different characteristics of different types of public opinion.

We define "high level of spread participation", "strong spread influence", "has offline actions", "government behavior", "multiple subject behavior" as "strong guiding factor", and the rest as "weak guiding factor". When combined with two strong guiding factors, the network public opinion is defined as strong, and when combined with two weak guiding factors, the network public opinion is defined as weak. The other combinations refer to fluctuating internet public opinions.

The classification above has definition of two dimensions, clear systems, and explicit purposes by analysing three elements: the media of public opinion, the events of public opinion, and the number of events of public opinion. Therefore, this classification provides a new way for subsequent studies.

However, this taxonomy still has some ambiguities in constructing classification system. For example, the government behavior can also be seen as single subject behavior so that the conclusion will have paradox. In this regard, one solution is to define explicitly, including supplementing "government behavior is not concluded in single subject behavior", or dividing "behaviors of stimulus" into two different dimensions. (table1, table 2) 
Table 1 Classification of types of network public opinion(a)

\begin{tabular}{c|c|c|c|c|c|c}
\hline medium & $\begin{array}{l}\text { high level of spread } \\
\text { participation }\end{array}$ & $\begin{array}{l}\text { low level of spread } \\
\text { participation }\end{array}$ & $\begin{array}{l}\text { strong spread } \\
\text { influence }\end{array}$ & $\begin{array}{l}\text { weak spread } \\
\text { influence }\end{array}$ & have offline actions & no offline actior \\
\hline $\begin{array}{c}\text { government } \\
\text { behaviour }\end{array}$ & strong & fluctuating & strong & fluctuating & strong & fluctuating \\
\hline $\begin{array}{c}\text { Jon-government } \\
\text { behaviour }\end{array}$ & fluctuating & weak & fluctuating & weak & fluctuating & weak \\
\hline
\end{tabular}

Table 2 Classification of types of network public opinion (b)

\begin{tabular}{|c|c|l|l|l|l|l}
\hline medium & $\begin{array}{l}\text { high level of spread } \\
\text { participation }\end{array}$ & $\begin{array}{l}\text { low level of spread } \\
\text { participation }\end{array}$ & $\begin{array}{l}\text { strong spread } \\
\text { influence }\end{array}$ & $\begin{array}{l}\text { weak spread } \\
\text { influence }\end{array}$ & have offline actions & no offline actions \\
\hline $\begin{array}{c}\text { single subject } \\
\text { behaviour }\end{array}$ & fluctuating & weak & fluctuating & weak & fluctuating & weak \\
\hline $\begin{array}{c}\text { multiple subject } \\
\text { behaviour }\end{array}$ & strong & fluctuating & strong & fluctuating & strong & fluctuating \\
\hline
\end{tabular}

\section{Taxonomy of Behaviors of Internet Users}

Luo Juan [6] analyzes the behaviors of netizens, and divides them into three types: rational and moderate type, emotional type, and extreme and ultra type. And also, this taxonomy that focused on netizens' complicated behaviors is a good approach.

Rational and moderate type includes network lurk, network dissemination and moderate posting(Figure1); emotional type includes emotional posting, emotional reply, internet signature and emotional internet creation; extreme and ultra type includes internet radical behaviors, such as radical posting, internet demonstration and hacker attack, and realistic aggressive behaviors.

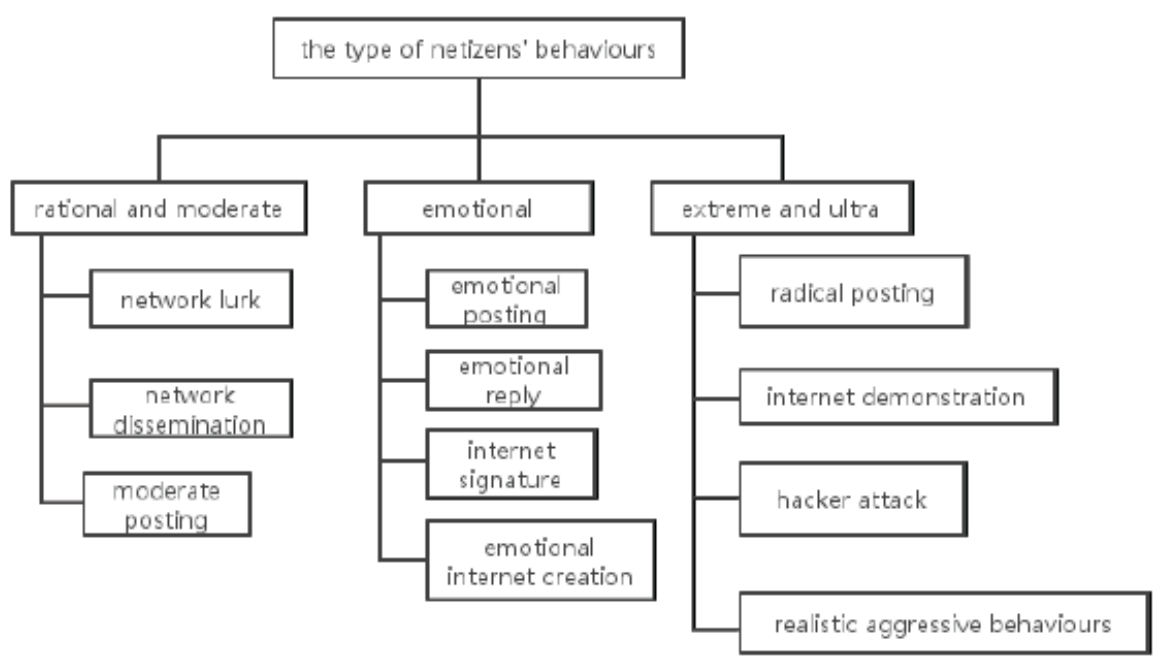

Figure 1 taxonomy based on the behaviors of netizens 
This classification is still more or less flawed, since it does not have a reasonable classification system and a clear logical structure about the further subclassification of these three types. Moreover, individual behaviors are caused by a variety of factors, and it is difficult to classify such behaviors without omissions.

Although it has some flaws, this classification also has several advantages. For example, neitzens' behaviors are easily to be captured by big data, and directly analysing them, government can set up database and develop appropriate measures dealing with emergency quickly and effectively. Thus, this classification is often used by scholars and regulatory authorities.

\section{Other Taxonomies}

Propaganda Department Public Opinion Information Bureau also mentioned that based on the component, network public opinion can be divided into factual information and views information, and based on the source, network public opinion can be divided into domestic network public opinion and overseas network public opinion.

Besides, based on existing forms, network public opinion can be divided into dominant public opinion and recessive public opinion; based on expressions, it can be divided into language public opinion and non-verbal public opinion; based on effects, it can be divided into positive public opinion and negative public opinion.

\section{Conclusion}

In the evolution of network public opinion, groups of Internet users, network medias, and public opinion are regarded as the three main factors of classification and each has advantages and disadvantages. According to different classification needs, scholars should take proper classification system. Building a harmonious network environment is an important component of harmonious socialist society of China; thus, establishing a rational classification is of great importance. Because proper and reasonable use of network public opinion can avoid the risks of network public opinion emergencies. In a nutshell, research on network public opinion classification lays a foundation for further research.

\section{References}

[1] Chunhua Zhang, network public opinion: Interpretation of sociology, social science literature press, 2012, 10, cover.

[2] Webster's online dictionary, merriam-webster.com/dictionary/sentiment.

[3] Publicity Department of the CPC Central Committee of public opinion information bureau, Network public opinion information theory and practice [M], Beijing Publishing House, 2009: 9-12.

[4] Zheng Kui, Shu Xueming, Yuan Hongyong, gold Sikui, The emergency network public opinion information classification method research, computer application and software, 2010, 05.

[5] Wang Guohua, Feng Wei, Wang Yalei, The study on the public opinion of network public opinion based on the classification of Journal of information, 2013, 05

[6] Luo Juan, Research on the behavior of Internet users in the network public opinion hotspot event, 14 - 22.

[7] Jiang Shenghong, The connotation and main characteristics of Internet public opinion", "media and communication, 151-152.

[8] Li Wenjing, Design and analysis of index system of network public opinion, information science, $2009,07$.

[9] Twenty-first China Internet development statistics report, 2008, 07. 
[10] Thirty-sixth China Internet development statistics report, 2015, 03. 